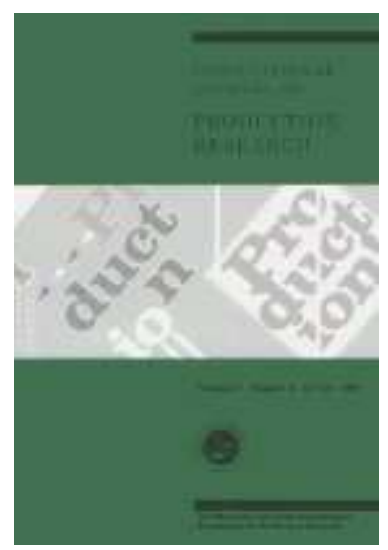

\title{
Revisiting the Pallet Loading Problem using a Discrete Event System Approach to minimize Logistic Costs
}

\begin{tabular}{|r|l|}
\hline Journal: & International Journal of Production Research \\
\hline Manuscript ID: & TPRS-2010-IJPR-0109 \\
\hline Manuscript Type: & Original Manuscript \\
\hline Author: & 02-Feb-2010 \\
\hline Complete List of Authors: & $\begin{array}{l}\text { Zuñiga, Catya; Autonomous University of Barcelona, } \\
\text { Telecommunication and Systems Engineering } \\
\text { Piera, Miguel; Autonomous University of Barcelona, Department of } \\
\text { Telecommunication and Systems Engineering } \\
\text { Narciso, Mercedes; Autonomous University of Barcelona, } \\
\text { Telecommunication and Systems Engineering }\end{array}$ \\
\hline Keywords: & $\begin{array}{l}\text { MANUFACTURING SYSTEMS, MANUFACTURING SYSTEMS } \\
\text { ENGINEERING }\end{array}$ \\
\hline Keywords (user): & $\begin{array}{l}\text { Pallet Loading Problem, Logistics, Coloured Petri Nets, Reachability } \\
\text { Tree, Heuristics }\end{array}$ \\
\hline
\end{tabular}

\section{s scholarONE" Manuscript Central}




\title{
Revisitizing the Pallet Loading Problem using a Discrete Event System Approach to minimize Logistic Costs
}

\author{
Catya Zúñiga, Miquel Ángel Piera, Mercedes Narciso \\ Department of Telecommunication and Systems Engineering, Autonomous University \\ of Barcelona, Barcelona, Spain
}

catyaatziry.zuniga@uab.cat; miquelangel.piera@uab.es; mercedes.narciso@uab.cat

(Received 13 September 2009)

\begin{abstract}
This paper presents a new challenging modelling approach to support different heuristics to tackle the Pallet Loading Problem (PLP). A discrete event system model to tackle the PLP, is specified using the Coloured Petri Net formalism in order to integrate the model with the industrial context in which the PLP must be solved. New events can be formalized in the model to implement different heuristics to consider the upstream (production) and downstream (transport) influence of the palletizing activity in the logistic flow. A state space analysis is performed to evaluate the different solutions to fit the maximum number of boxes on a rectangular pallet, supporting the inherent box diversity (heterogeneous palletizing problems) of present production and distribution logistic systems. The heuristics implemented show that acceptable occupancy results can be obtained without requiring the exhaustive evaluation of the different feasible combination. The results demonstrate that it outperforms other approaches which have been suggested for this type of problem. Potentially useful extensions of the work are discussed.
\end{abstract}

Keywords: Pallet Loading Problem, Logistics, Coloured Petri Nets, Reachability Tree, Heuristics

\section{Introduction}

The Palletizing has become an important issue not only in the transportation industry, but also a very important piece in the Supply Chain Management due to upstream and downstream influence in the logistics flow Curcio and Longo (2009), Tiacci, and Saetta (2009). It is well known that pallets filled in an optimal way reduce transportation and warehousing costs among others. Nevertheless, there are some hidden costs in which usually the palletizing plays a key role. The palletization of different box sizes in high diversity production systems and distribution centres force sometimes to accumulate a high quantity of boxes of the same type to optimize the pallet volume while unnecessarily increasing the lead time. Due to fierce cost competitivity, the palletizing should be seen also as an important link in all those logistics area where orders from customers must be prepared, placing the packages on pallets in an optimal way for the issue. A pallet filled in optimal conditions considers different aspects such as time spent in the process, stability and space utilization which is defined to be the percentage of pallet space or volume occupied by the load products. It is easy to note that a higher space utilization factor requires a smaller number of pallets; hence, a higher efficiency in the palletizing is obtained. Recent issues in transportation and storage costs have highlighted the importance of an optimal palletization, both in transit and in the warehouse. Transportation and 
warehouse costs are directly related to the type and number of pallets used for a shipment, which, in turn, is directly linked to proper space utilization, therefore an optimal filling of a pallet reduces the shipment costs as well as increases the stability and support of the load. A review of classical PLP approaches that focus on the manufacturer problem which regularly transports large quantities of a reduced set of master box types can be found in Abdou and Yang (1994), Alvarez-Valdes, Parreño and Tamarit (2005), Bischoff and Dowsland (1982), Bischoff (2006), Chua, Narayanan and Loh (1998), Gehring, Menschner and Meyer (1990), George and Robinson (1980), Han, Knott and Egbelu (1989), Ivancic, Mathur and Mohanty 1989), Lim, Rodrigues and Yang (2005)

Most of these classical packing strategies are based on the wall building approach presented by George and Robinson (1980), with some adaptations such as Xue and Lai (1997), Bischoff (1996), Gehring, Menschner, and Meyer (1990) and Bischoff and Dowsland (2006) among others. The wall building approach is an heuristics that loads the pallet with columns of boxes; each column is composed of a set of boxes stacked vertically and the column stacks are no higher than the maximum allowable pallet height, Abdou and ElMasry (1999). This method itself is a greedy heuristics which can lead to weak final solutions, Dowsland, W.B. 1991. Other methods using spatial representation presented by Ngoi, Tay, and Chua (1994) and Chua, Narayanan, and Loh (1998) reduce the problem to maximum set problem or an integer programming problem. For methods based on the spatial representation such as the one presented by Han, Knotta and Egbelu(1989), empty volume search routines are used to generate small spaces, whereas the successful utilization of these small spaces is difficult.

For methods based on graph theory and integer programming Ivancic, Mathur, and Mohanty (1989), some disadvantages appear due to model simplification aspects and the inherent difficulty of the combinatorial nature of these problems. Some approaches to tackle the PLP such as Alvarez-Valdes, Parreño and Tamarit (2005) and Martins and Dell (2008), assume that all boxes have identical rectangular dimensions. On the whole, published works generally give successful 
implementations to solve particular PLP and provide some interesting insights into the various views on how successful packing can be best achieved, Lim, Rodrigues and Yang, (20059.

Despite these studies present feasible solutions for the cargo problem, there are a considerable number of scenarios which have received only fairly limited attention so far, and very poor solutions are obtained when classical algorithms are applied.

An example of such scenarios is the loading patterns which are restricted to either layered or stacking columns. In previous studies, bins or containers are also considered as large regular-shaped rectangular boxes which can be loaded by vertical layers (stacking columns) and boxes are supported by its walls. This may be true when the study is focused in filling containers but the loading pattern in the pallet must be different because of the role that stability plays. In layered type models, the main disadvantage is that boxes must have identical height.

But maybe the most relevant scenario appears when the cargo to be palletized consists of heterogeneous boxes (different dimensions), which is the opposite of the manufactures' problem because the empty space generated by the previously loaded boxes is so hard to treat. Distributors' centres are a particular case of this scenario, characterized by a high diversity of box types' where items of varying sizes representing an order from a customer - have to be loaded onto a pallet and delivered in different destinations in a predefined sequence.

In Abdou and ElMasry (1999), a challenging approach to reuse rectangular shaped three-dimensional empty space found anywhere at any given time on a pallet is presented, which is quite similar to free space areas reuse presented in this paper. However the use of CPN formalism contributes to develop structured models much 
more easy to maintain and adapt to particular operational conditions in which different heuristics can be designed and tested. As problem definition can vary based on the type of box (homogeneous versus heterogeneous) and input requirement (deterministic versus stochastic) this work is based on the "three-dimensional Bin Packing Problem (BPP)" concept which is characterized by a packing set of nonidentical rectangular cargo-boxes into a minimum number of three-dimensional identical bins or containers, Dowsland (1991). Other scenarios have recently emerged, some of them related to intermodal transport systems, as it is the case of air-cargo, which requires a highly flexible palletizing system.

This paper presents a challenging modelling approach in which the Coloured Petri Net formalism has been used to specify the PLP in such a way that upstream and downstream logistic information flow can be easily formalized to improve the search of feasible solutions for a certain particular industrial context. The most important advance lies in the fact that the model is flexible enough to accept different information flows to tackle the PLP according to the operational context to be optimized, Piera, Zuniga and Mujica, (2009). Thus, different availability aspects can be easily modelled by formalizing the events in CPN that specify the availability of boxes in a local stock, the arrival of boxes from the production system through a conveyor or from a warehouse. In a similar way, the model scope can be extended with downstream transportation aspects such as capacity and weight truck constrains. Coloured Petri Net models supports the specification of time delays associated to events Narciso, Piera and Guasch, (2009), thus the proposed PLP model could also consider time restrictions not only on the delivery of the pallets to support an efficient supply chain management but also on the palletizing operations. 
Furthermore, different colours (i.e. attributes) can be added to the PLP model to consider other aspects such as degrees of sturdiness/fragility, weigh category, size ordering, or a stability priority, among others, which can be used as constraints to guide the search through the state space for a feasible or optimal PLP solution, Piera et al. (2004).

The organization of this paper is the following: Section II presents a general description of the palletizing model developed at a Discrete Event System (DES) abstraction level. Section III presents a brief introduction to the CPNs. In Section IV the model is described in detail and in Section V different computational experiments with homogeneous and heterogeneous systems are reported. In Section VI some heuristics are added to the model based on different type of approach and different computational experiments for this model are reported. Finally conclusions are presented in Section VII.

\section{Discrete event approach to the PLP}

Given a set of $n$ different types of rectangular-shaped boxes (or arrangement of several such boxes) with known dimensions $l x_{i}, l y_{i}, l z_{i}($ with $i=1 \ldots n$ ) the model solves the orthogonal packing onto a rectangular pallet of fixed dimensions, slx * sly.

Without a loss of generality, the model considers that the product must be packed orthogonally (i.e. with the edges of the boxes parallel to the edges of the pallet) and can be placed in different layers. Furthermore, boxes to be placed can have a time stamp attached that can be used to specify when the box will be available for packing (i.e. a rough constraint of the production system).

When a box is positioned inside the pallet the space is partitioned or fragmented into several rectangular shaped spaces called free surfaces. Figure 1 
illustrates two free surfaces that are generated after placing a box. The Total free surface concept refers to the total available space inside the pallet i.e. the sum of the $n$ different free surfaces previously generated. Each time a box is positioned inside the pallet, some information is updated to support a proper description of the pallet state: coordinates, dimensions and orientation of each box, coordinates and dimension of each new free surface generated as a consequence of positioned boxes.

\section{INSERT FIGURE 1}

To illustrate the importance of a proper state oriented pallet specification of the free surface area, let's consider again Figure 1, in which the box placed in the left bottom corner has generated two new free rectangular surface areas. To place another box in the pallet the two free surfaces must be evaluated to determine if the box can be inserted inside one of both areas or it is necessary to compute a new free area as a result of a combination of the two fragmented free areas. Thus, events describing different possibilities for placing a box in a pallet should be computed in an efficient way the different pallet layout configurations.

When a box has to be placed inside the pallet there are two possibilities that can be described as a relationship between boxes dimensions and free surface areas characteristics:

(1) the box fits inside a free surface

(2) the box does not fit inside a free surface.

By considering again the pallet's configuration described in Figure 1, the new box could be placed in the free surface area $n^{o} 1$, but due to dimension constraints the box couldn't be placed in the free surface area $n^{o} 2$ (even if the box is rotated). However, there is also a combination of the two contiguous free surface areas that would support the placement of box $n^{o} 2$. 
The fragmentation/defragmentation free surface areas has been solved very efficiently, by supporting the CPN specification of virtual boxes, in which a box is fragmented in contiguous virtual boxes that must be placed in contiguous free surface areas. Figure 2, illustrates the virtual box concept in which a box to be placed (box $n^{o}$ 2 ) is fragmented in two virtual boxes to be fitted in the free surface areas.

\section{INSERT FIGURE 2}

\section{Coloured Petri Net optimization approach}

Coloured Petri Nets (CPN) according to Jensen, (1997) have proved to be successful tools for modelling complex systems due to several advantages such as the conciseness of embodying both the static structure and the dynamics, the availability of the mathematical analysis techniques, and its graphical nature, Piera et al (2004).

The main CPN components that fulfill the modelling requirements for flexible systems, Piera, Narciso and Buil (2009), are:

- Places: They are very useful to specify both queues and logical conditions. Graphically represented by circles.

- Transitions: They represent the events of the system. Represented graphically by rectangles.

- Input Arc Expressions and Guards: Are used to specify which type of tokens can be used to fire a transition.

- Output Arc Expressions: Are used to specify the system state change that appears as a result of firing a transition.

- Colour Sets: Determines the types, operations and functions that can be used by the elements of the CPN model. Token colours can be seen as entity attributes of commercial simulation software packages

- State Vector: The smallest information needed to predict the events that can appear. The state vector represents the number of tokens in each place, and the colours of each token.

The Colour sets will allow the modeller to specify the entity attributes. The output arc expressions allow to specify which actions should be coded in the event routines associated with each event (transition). The input arc expressions allow to specify the event pre-conditions. The state vector will allow the modeller to 
understand why an event appears, and consequently to introduce new pre-conditions (or remove them) in the model, or change some variable or attribute values in the event routines to lock enabled events.

From the Operational Research (OR) point of view, a CPN model can provide the following mathematical structures:

- Variables: A variable can be identified for each colour specified in every place node.

- Domains: The domains of the variables can be easily determined by enumerating all the tokens colours specified in the initial state.

- Constraints: Can be obtained straightforward from the arc and guard expressions. Arc expressions can contain constant values, colour variables or mathematical expressions.

From the Artificial Intelligence (AI) point of view, the reachability tree of a

CPN model allows to determine:

- All the events that could appear according to a particular system state (Figure 3).

- All the events that can set off the firing of a particular event.

- All the system states (markings) that can be reached starting from a certain initial system operating conditions known as initial marking and represented by $M_{0}$.

- The firing sequence to drive the system from a certain initial state to a desired end-state.

\section{INSERT FIGURE 3}

\section{PLP CPN specification}

The PLP model has been specified in the CPN formalism. The box placement casuistic is decomposed into four set of transitions. The first two set of transitions are casuistic for the box placement (see Figure 4) while the other two casuistic are for the virtual box placement.

\section{INSERT FIGURE 4}

As shown in Figure 4, when a box does not fit into a free surface, one or more virtual boxes emerge as a consequence of the dimensions and position of the free surface. The placement of these virtual boxes is outlined in Figure 5. 
Figure 6 illustrate the main differences between a subset of transitions (i.e. T42 to T46) that have been generated by another transition (Figure 5). It is not hard to see that even if dimensions of the virtual box are the same in each transition, coordinates where placement will be done are not necessary the same. Therefore some restrictions are added to each transition to define each situation shown.

\section{INSERT FIGURE 6}

Finally, a transition (T1) allows $90^{\circ}$ box rotations as long as they are placed with edges parallel to the pallet's edges, i.e., the placement must be orthogonal, and each box can be rotated only once.

\section{A. Terminology}

Table 1and 2 summarize the colours and places used to describe all the information required to fit boxes in a pallet using the abstraction level of the pallet maker process introduced in this section.

\section{B. Event Specification Examples}

An example of an event that fits a box in a free surface area when the length $x$ and $y$ of the box are shorter than the length $x$ and $y$ of a free surface (see the guard expression). It should be noted that under these state conditions, the free surface used to place the box is fragmented in two new free surfaces that can be used to place future boxes.

Figure 7 illustrates the event that formalizes fitting a box into a free surface when the length $x$ and/or $y$ of the box are longer than the length $x$ and $y$ of a free surface, respectively. Node $P 1$ holds tokens describing the boxes to be placed while $P 2$ holds tokens which contain information that represents the free surfaces. Therefore, two virtual boxes are computed and added in place $P 3$ in which coordinates and dimensions are hold. $P 4$ is used to control and coordinate the 
sequence of events to solve a virtual box placement before any other box could be chosen to be placed in the pallet. Colour ge changes from 0 to 1 in the output arc (T31 -> P4) to mark that the original box has been divided into one or more virtual boxes; the total free surface is also decremented in according to the portion used by the virtual box (i.e. $s l y * s l x)$ which are the dimensions of the free surface used. The number of virtual boxes $g n c v$ is incremented in two units, which are the two virtual boxes generated due to the firing of this transition.

\section{INSERT FIGURE 7}

To place a virtual box, two different set of events have been considered; the first set (T41 to T48) represents the placement of a virtual box that do not overcome a free surface, while the second set (T51 to T58) of events support the fitting of a virtual box which does overcome the surface and generates more virtual boxes.

Figure 8 illustrates the idea of placing virtual boxes. It is assumed that part of the original box has been placed and it remains only one virtual box to be placed. In this situation, transition called $T 58$ would be fired (see Figure 9), in which a virtual box is placed generating one virtual box, which is indicated by the output arc of place $P 3$. Also another free surface is generated, output arc of place $P 2$. Finally as explained in the transition called $T 31$, total free surface is decremented and the number of virtual boxes keeps steady because one virtual box is placed but another is generated.

\section{INSERT FIGURE 8}

Additionally to all these events that specify how to place a box into a free surface, there is a particular event that allows changing the orientation of the box in order to fit better in a free surface. This event could happen at any time but can only be fired only once per each box. 


\section{INSERT FIGURE 9}

\section{Experiments and results}

The reachability tree relies on the computation of all reachable states and state changes of the system, and it is based on an explicit state enumeration. Thus, by means of the state space exploration of the CPN model developed, it is possible to check the different combinations in which boxes can be fitted in the pallet, and choose the one that minimizes a certain cost function: free surface area not properly used due to space fragmentation, delays due to boxes time stamps, etc.

A packing pattern of a pallet is said to be feasible if the boxes fit completely within a pallet and the specification of this final state consists to force all the tokens in node $P 1$ to set the colour $c e$ with value 2 , mathematically represented by the vector:

$$
M f=[* ; *, *, *, *, *, *, 2), *, *, *]
$$

Thus, any state with all the tokens in place $P 1$ with colour $c e=2$ can be considered a feasible solution since all the boxes has been fitted inside the surface.

Several experiments exploring the reachability tree have been performed in two different simulation tools (CPNTools and Piera et all (2004)) to illustrate the benefits of the CPN model. Experiments have been divided based on the box's typology:

- Case I: Test data are shown in Table 3. All box types are identical in this case. Homogeneous systems.

- Case II: Test data are shown in Table 4. Box types are different in this case. Heterogeneous systems.

Boxes must be accommodated in a surface of $100 \times 100$ units Results for a feasible solution of Tests 1 to 5 of case I and Test 2 to 8 of case II are shown in Table 5 and 6, respectively. In these Tables final marking of all places as well as the graphical representation are shown. Using information on place $P 4$, it can be noticed 
that all boxes have been placed successfully inside the pallet and the free space unused is the minimal. This means that $100 \%$ pallet utilisation can be obtained with all boxes properly placed.

Even feasible solutions are found with both tools, computational time is considerably too large, and therefore two different heuristics have been developed to decrement computational time without losing feasible solutions.

\section{Specification of heuristic rules in CPN to improve the PLP search}

Since the exploration of the whole reachability tree is quite expensive in terms of computer memory requirements and computational time, some heuristics have been designed to avoid the evaluation of certain sequence of events that will not lead a good solution. In Piera et all (2004) and Piera, Mujica and Guasch, (2007), the main aspects of a reacheability tree analysis tool implemented to support heuristics and knowledge representation is outlined. This tool has been used to get feasible results solving the PLP using a reduced number of different boxes types by means of formalizing specific knowledge in terms of heuristics.

\section{Heuristic based on typology boxes}

A heuristic has been developed and implemented in the model so boxes are placed by groups of the same type (i.e. boxes of the same dimensions). Thus, if a box of certain type is chosen, the model is forced to place all boxes of this type before any other box type could be chosen.

This heuristic is specified by the introduction of two more transitions to the model, two places (see Table 7) and two colours. These new colours are $n c$ and $t p$; colour t $p$ is a control variable which can take a 0 value if the box type has never been 
picked and $t p=1$ if it has been picked; the other colour added to the model is $n c$, representing the number of boxes of the same type.

Place $P 1$ has been modified by removing the colour $c e$ and adding the two new colours $t p$ and $n c$ to determine if a certain box type has been already placed in the pallet.

To allow a change on the type of boxes to be fitted in the pallet, a second transition $T C$ has been implemented that is activated when all the boxes of the same type have been placed (colour $n c=0$ ). Once $T C$ has been fired, colour $t p$ is updated from $O$ to 1 to activate the selection of a new type of box (place $C O$ is used to trace information changes). Several experiments exploring the reachability tree have been performed and results are presented in case III.

- Case III: Test data are shown in Table 8. Heterogeneous systems using heuristic based on typology boxes.

Boxes must be accommodated in a pallet surface of $100 \times 100$ units.

Results for a feasible solution of tests 9 to 12 of case III are shown in Table 9. In this Table the final marking of all places as well as the graphical representation is shown. Using information on place $P 4$, it can be noticed that all boxes are placed successfully inside the pallet and the free space unused is minimal. This means that $100 \%$ pallet utilisation can be obtained with all boxes properly placed therefore this heuristic reaches a feasible solution.

\section{Based row placement Heuristic}

A second heuristic has been designed and integrated in the CPN model so boxes are placed by rows independent of the box's type. Thus, a box is placed following the same coordinates in the axis $y$ of the previous box. A new row is initialized by fitting a new box, when no more boxes can be fitted in the previous row. 
This heuristic is specified by means of a new transition (T8) (see Figure10a), and the rest of transitions have been modified by two places, $P$ and $C O$ (see Table 10 and Figure 10b) and four colours (scxl, scyl,slxl,slyl) to represent the coordinates and dimensions of the new row in axis $x$ and $y$. When a row is full of boxes or there is not a box that fits in the row, a change of row is allowed.

\section{INSERT FIGURE 10}

A place called $P$ is added to the model and it is used to store coordinates and dimensions of free surfaces that might be used in the next row. A new place $C O$ was introduced to store placed box information.

Several experiments exploring the reacheability tree have been performed in CPN Tools.

- Case IV: Test data are shown in Table 11. Heterogeneous systems using heuristic based on row placement.

Boxes must be accommodated in a pallet surface of $100 \times 100$ units.

Results for a feasible solution of tests 13 to 16 of Case IV are shown in Table 12. In this Table the final marking of all places as well as the graphical representation is shown. Using information on place $P 4$, it can be noticed that the all boxes are placed successfully inside the pallet and the free space unused is the minimal. This means that $100 \%$ pallet utilisation can be obtained with all boxes properly placed; therefore this heuristic reaches a feasible solution.

Both heuristics has been implemented mainly by specifying new guard expressions in the box placement transition. In a similar way to priorize the use of small/large fragmented free spaces areas new guard expressions could be designed to choose the most promising tokens from place node $P 2$ according to the token (box) chosen from place node $P 1$. 


\section{Conclusions and further work}

A discrete event approach to optimize the PLP has been specified in CPN formalism. One of the most important features of the developed model is the flexibility to support production and distribution constraints. The definition of new colours attached to box tokens, could be used as new prerequisites in the PLP solution by considering aspects such as: weight, size and stability constraints.

Despite the examples presented in this paper focus on the which illustrate the static pallet packing problems; the CPN model can be extended to a Timed Coloured Petri Net model in which time components (i.e. simulation clock and time stamps) can used to tackle the PLP as part of a supply chain system. Thus, the specification of a new transition to feed boxes in place node P1 could be used to represent box availability.

The PLP packing strategy has been developed without considering extra constraints that would not affect operational benefits; otherwise the space solution would be too rigid and therefore incapable of managing the inherent diversity of heterogeneous pallet problems. The heuristics formalized in CPN illustrate the flexibility of adapting the model to obtain better computer performances when optimizing the PLP without losing feasible solutions.

For practical application, the model will be adapted with weight factors and delays to optimize pallet operations in a real industrial context. As a future work, the model will be adapted to consider the air cargo operations, in which it is well known that bays in most passenger aircrafts, fly empty because the time required to load non used passenger belies overcomes acceptable turnaround times. Available weight and volume is known at the very last moment, once all passenger baggage has been 
checked, which usually is 30 minutes before flight departure. Thus, time aspects together with volume and weight constraints will be considered in the design of new heuristics to optimize the palletizing operation in air cargo platforms.

\section{ACKNOWLEDGMENTS}

This work is partly funded by the Science and Innovation Ministry of the Spanish Government "Discrete Event Simulation Platform to improve the flexible coordination of land/air side operations in the Terminal Maneuvering Area (TMA) at a commercial airport" CICYT Spanish program TRA200805266/TAIR.

\section{References}

Abdou, G., and Elmasry, M., 1999. 3D random stacking of weakly heterogeneous palletization problems, International Journal of Production Research, 37 (7), $1505-1524$.

Abdou, G., and Yang, M., 1994. A systematic approach for the three-dimensional palletization problem, International Journal of Production Research, 32 (10), $2381-2394$.

Alvarez-Valdes, R., Parreño, F., and Tamarit, J.M., 2005. A branch-and-cut algorithm for the pallet loading problem, Computers \& Operations Research, 32, 3007-3029.

Bischoff, E. and Dowsland, W.B., 1982. An application of the microcomputer to product design and distribution, Operational Research Society Journal, 33, 271280.

Bischoff, E.E., 2006. Three-dimensional packing of items with limited load bearing strength, European Journal of Operational Research 168, 952-966. Chua, C.K., Narayanan, V., and Loh, J., 1998. Constraint-based spatial representation technique for the container packing problem, Integrated Manufacturing Systems, 9 (1), 23-33.

CPNTools, Online: http://wiki.daimi.au.dk/cpntools/cpntools.wiki\}

Curcio, D., and Longo, F., 2009, Inventory and Internal Logistics Management as Critical Factors Affecting the Supply Chain Performances, International Journal of Simulation \& Process Modelling, 5 (2), 127-137.

Dowsland, W.B. 1991. Three dimensional packing: solution approaches and heuristic development, International Journal of Production Research 29, 16371685.

Gehring, H., Menschner, K. and Meyer, M., 1990. A computer-based heuristic for packing pooled shipment containers, European Journal of Operational Research, 44, 277-288

George, J.A. and Robinson, B.F., 1980. A heuristic for packing boxes into a container, Computer and Operational Research, 7, 147-156.

Han, C.P., Knott, K. and Egbelu, J.P., 1989. A heuristic approach to the threedimensional cargo-loading problem, International Journal of Production Research, 27 (5), 757-774.

Ivancic, N., Mathur, K. and Mohanty, B.B., 1989. An integer programming based heuristic approach to the three dimensional packing problem, Journal of Manufacturing and Operations Management, 2, 268-298. 
Jensen, K, 1997. Coloured Petri Nets: Basic Concepts, Analysis Methods and Practical Use, 2, Berlin: Springer-Verlag.

Kristensen, M.L., Christensen, S. and Jensen, K., 1998. The practitioner's guide to coloured Petri nets, Springer-Verlag, 98-132.

Lim, A., Rodrigues, B. and Yang, Y., 2005. 3-D Container Packing Heuristics Applied Intelligence, Springer Science + Business Media, 122, 125-134. Martins, G.H.A., Dell, R.F., 2008. Solving the pallet loading problem, European Journal of Operational Research, 184, 429-440.

Narciso, M.E., Piera, M.A., and Guasch, A., 2009. A Methodology for Solving Logistic Optimization Problems through Simulation, Simulation, [online] first published on December 2, Available from: http://sim.sagepub.com/pap.dtl Ngoi, B.K.A., Tay, M.L. and Chua, E.S., 1994. Applying spatial representation techniques to the container packing problem, International Journal of Production Research 32,111-123.

Piera, M. A., Narciso M.E., Guasch, A., Riera, D., 2004. Optimization of Logistic and Manufacturing Systems through Simulation: A Colored Petri Net-Based Methodology, Simulation, Transactions of The Society for Modeling and Simulation International, 8, 121-129.

Piera, M.A., Mujica M.A. and Guasch, A., 2007. An efficient CPN modeling approach to tackle the pallet packing problem, in Proceedings of the 6th EUROSIM Congress on Modeling and Simulation, September 9-13, Ljubljana. Piera, M.A., Narciso M.E. and Buil R., 2009. Flexible Manufacturing Systems, in Simulation-based case-studies in Logistics: education and applied research book. Springer, 109-126.

Piera, M.A., Zuniga, C., and Mujica, M., 2009. A Pallet Packing CPN Optimization Approach for Distribution Center, Automatika 50, 1-2, 29-38. Tiacci, L., and Saetta, S., 2009. An approach to evaluate the impact of interaction between demand forecasting method and stock control policy on the inventory system performances, International Journal of Production Economics, Elsevier, 1,118, 63-71.

Xue, J. and Lai, K.K., 1997. Effective methods for a container packing operation, Mathl. Comput. Modelling, 25 (2), 75-84. 
Table 1. Place specification

\begin{tabular}{|c|l|l|}
\hline Place & \multicolumn{1}{|c|}{ Colour } & \multicolumn{1}{c|}{ Meaning } \\
\hline P1 & 1'(idc,cx,cy,cz,lx,ly,lz,cr,ce) & Boxes \\
\hline P2 & 1'(scx,scy,slx,sly) & Free Surfaces \\
\hline P3 & 1'(idc,cx,cy,cz,lx,ly,lz,ce) & Virtual Boxes \\
\hline P4 & 1'(ge,gz,gsf,gncv,gnc) & Global Variables \\
\hline
\end{tabular}


Table 2. Colour specification

\begin{tabular}{|c|c|c|}
\hline Colour & Definition & Meaning \\
\hline idc & Integer & Box identifier \\
\hline $\mathrm{cr}$ & Integer & $\begin{array}{l}0: \text { original orientation } \\
1 \text { : rotated } 90^{\circ} \mathrm{wrt} \mathrm{z}\end{array}$ \\
\hline ce & Integer & $\begin{array}{l}0: \text { not assigned } \\
\text { 1: working } \\
\text { 2: placed in the pallet }\end{array}$ \\
\hline $\mathrm{cx}$ & Real & $\begin{array}{l}\text { Coordinate } \mathrm{x} \text { where the box is } \\
\text { located }\end{array}$ \\
\hline cy & Real & $\begin{array}{l}\text { Coordinate } y \text { where the box is } \\
\text { located }\end{array}$ \\
\hline $\mathrm{cz}$ & Real & $\begin{array}{l}\text { Coordinate } \mathrm{z} \text { where the box is } \\
\text { located }\end{array}$ \\
\hline $1 \mathrm{x}$ & Real & Box length in coordinate $\mathrm{x}$ \\
\hline ly & Real & Box length in coordinate y \\
\hline $\mathrm{lz}$ & Real & Box length in coordinate $\mathrm{z}$ \\
\hline $\operatorname{scx}$ & Real & $\begin{array}{l}\text { Coordinate } \mathrm{x} \text { where the surface } \\
\text { is located }\end{array}$ \\
\hline scy & Real & $\begin{array}{l}\text { Coordinate y where the surface } \\
\text { is located }\end{array}$ \\
\hline slx & Real & Surface length in coordinate $\mathrm{x}$. \\
\hline sly & Real & Surface length in coordinate y. \\
\hline ge & Integer & $\begin{array}{l}\text { 0: A Box can be placed in the } \\
\text { pallet } \\
\text { 1: Box to be assigned } \\
\text { 2: Looking for a surface } \\
\text { 3: Evaluating the new } \\
\text { fractioned surfaces }\end{array}$ \\
\hline $\mathrm{gz}$ & Integer & Indicates the pallet floor \\
\hline gsf & Real & Total free surface in the pallet \\
\hline gncv & Integer & Number of virtual boxes \\
\hline gnc & Integer & Total number of boxes \\
\hline
\end{tabular}


Table 3. Test data for case I

\begin{tabular}{|c|c|c|c|}
\hline $\begin{array}{l}\text { Test } \\
\text { No. }\end{array}$ & $\begin{array}{l}\text { No. of } \\
\text { boxes }\end{array}$ & $\begin{array}{l}\text { No. of } \\
\text { boxes' type }\end{array}$ & $\begin{array}{c}\text { Dimensions } \\
(\mathrm{x}, \mathrm{y}, \mathrm{z})\end{array}$ \\
\hline 1 & 2 & 1 & $100,50,10$ \\
\hline 2 & 5 & 1 & $100,20,10$ \\
\hline 3 & 10 & 1 & $50,20,10$ \\
\hline 4 & 9 & 1 & $30,30,10$ \\
\hline 5 & 6 & 1 & $30,40,10$ \\
\hline
\end{tabular}


Table 4. Test data for case II

\begin{tabular}{|c|c|c|c|c|}
\hline $\begin{array}{l}\text { Test } \\
\text { No. }\end{array}$ & $\begin{array}{l}\text { No. of } \\
\text { boxes }\end{array}$ & $\begin{array}{l}\text { Boxes' } \\
\text { types }\end{array}$ & $\begin{array}{l}\text { No. of } \\
\text { boxes' type }\end{array}$ & $\begin{array}{l}\text { Dimensions } \\
(\mathrm{x}, \mathrm{y}, \mathrm{z})\end{array}$ \\
\hline \multirow[b]{2}{*}{6} & \multirow[b]{2}{*}{2} & \multirow[b]{2}{*}{2} & 1 & $100,20,10$ \\
\hline & & & 1 & $100,80,10$ \\
\hline \multirow{4}{*}{7} & \multirow{4}{*}{4} & \multirow{4}{*}{4} & 1 & $40,30,10$ \\
\hline & & & 1 & $40,70,10$ \\
\hline & & & 1 & $60,20,10$ \\
\hline & & & 1 & $60,80,10$ \\
\hline \multirow[b]{2}{*}{8} & \multirow[b]{2}{*}{7} & \multirow[b]{2}{*}{2} & 3 & $40,50,10$ \\
\hline & & & 4 & $20,50,10$ \\
\hline
\end{tabular}


Table 5. Feasible solutions for case I

\begin{tabular}{|c|c|c|}
\hline \multicolumn{3}{|c|}{ Test 1} \\
\hline Place & Colour & $\begin{array}{l}\text { Graphical } \\
\text { representation }\end{array}$ \\
\hline P1 & $\begin{array}{l}1^{\prime}(1,0,0,0,100,50,10,0,2)++ \\
1^{-}(1,50,0,0,100,50,10,0,2)\end{array}$ & \\
\hline P2 & empty & \\
\hline $\mathrm{P} 3$ & empty & \\
\hline P4 & empty & \\
\hline \multicolumn{3}{|c|}{ Test 2} \\
\hline P1 & $\begin{array}{l}1^{\top}(1,0,0,0,20,100,10,1,2)+ \\
1^{`}(1,20,0,0,20,100,10,1,2) \\
+1^{`}(1,40,0,0,20,100,10,1,2) \\
+1^{`}(1,60,0,0,20,100,10,1,2) \\
+1^{`}(1,80,0,0,20,100,10,1,2) \\
\end{array}$ & \\
\hline $\mathrm{P} 2$ & empty & \\
\hline P3 & empty & \\
\hline $\mathrm{P} 4$ & empty & \\
\hline \multicolumn{3}{|c|}{ Test 3} \\
\hline P1 & 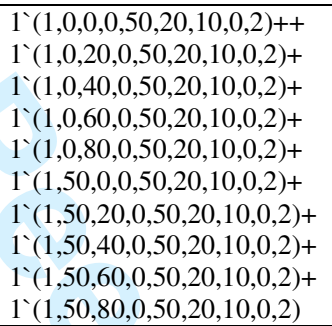 & \\
\hline P2 & empty & \\
\hline P3 & empty & \\
\hline $\mathrm{P} 4$ & empty & \\
\hline \multicolumn{3}{|c|}{ Test 4} \\
\hline $\mathrm{P} 1$ & $\begin{array}{l}1(1,0,0,0,30,30,10,0,2)+ \\
1(1,0,30,0,30,30,10,0,2)+ \\
1(1,0,60,0,30,30,10,0,2)+ \\
1(1,30,0,0,30,30,10,0,2)+ \\
1(1,30,30,0,30,30,10,0,2)+ \\
1(1,30,60,0,30,30,10,0,2)+ \\
1(1,60,0,0,30,30,10,0,2)+ \\
1(1,60,30,0,30,30,10,0,2)+ \\
1(1,60,60,0,30,30,10,0,2)\end{array}$ & \\
\hline P2 & $\begin{array}{l}1^{\prime}(0,90,30,10)+1^{\prime}(0,30,90, \\
30,10)+1^{`}(60,90,30,10)+ \\
1^{\prime}(90,0,10,100)\end{array}$ & \\
\hline P3 & empty & \\
\hline P4 & $1^{\prime}(0,0,1900,0)$ & \\
\hline \multicolumn{3}{|c|}{ Test 5} \\
\hline $\mathrm{P} 1$ & $\begin{array}{l}1(1,0,0,0,40,30,10,1,2)++ \\
1(1,0,30,0,30,40,10,0,2)++ \\
1(1,40,0,0,30,40,10,0,2)++ \\
1(1,40,40,0,30,40,10,0,2)+ \\
1(1,70,0,0,30,40,10,0,2)++ \\
1(1,70,40,0,30,40,10,0,2)\end{array}$ & \\
\hline $\mathrm{P} 2$ & $\begin{array}{l}1^{\top}(0,70,30,30)+1^{`}(30,30,10, \\
70)+1 `(40,80,30,20)+ \\
1(70,80,30,20)\end{array}$ & \\
\hline P3 & empty & \\
\hline $\mathrm{P} 4$ & $1^{\prime}(0,0,2800,0)$ & \\
\hline
\end{tabular}


Table 6. Feasible solutions for case II

\begin{tabular}{|c|c|c|}
\hline \multicolumn{3}{|c|}{ Test 6} \\
\hline Place & Colour & $\begin{array}{l}\text { Graphical } \\
\text { representation }\end{array}$ \\
\hline P1 & $\begin{array}{l}1 `(1,0,0,0,100,80,10,0,2)++1 \\
(1,0,80,0,100,20,10,0,2)\end{array}$ & \\
\hline $\mathrm{P} 2$ & empty & \\
\hline P3 & empty & \\
\hline $\mathrm{P} 4$ & empty & \\
\hline \multicolumn{3}{|c|}{ Test 7} \\
\hline $\mathrm{P} 1$ & $\begin{array}{l}1^{`}(1,0,0,0,60,80,10,0,2)++ \\
1 `(1,0,80,0,60,20,10,0,2)++ \\
1 `(1,60,0,0,40,70,10,0,2)++1 \\
(1,60,70,0,40,30,10,0,2)\end{array}$ & \\
\hline $\mathrm{P} 2$ & empty & \\
\hline P3 & empty & \\
\hline $\mathrm{P} 4$ & empty & \\
\hline \multicolumn{3}{|c|}{ Test 8} \\
\hline P1 & $\begin{array}{l}1^{`}(1,0,0,0,40,50,10,0,2)++ \\
1^{`}(1,0,50,0,40,50,10,0,2)++1^{`} \\
(1,40,0,0,20,50,10,0,2)++ \\
1^{`}(1,40,50,0,20,50,10,0,2)+1^{`} \\
(1,60,0,0,40,50,10,0,2)++1^{`}(1 \\
, 60,50,0,20,50,10,0,2) \\
1^{`}(1,80,50,0,20,50,10,0,2)\end{array}$ & \\
\hline $\mathrm{P} 2$ & empty & \\
\hline P3 & empty & \\
\hline $\mathrm{P} 4$ & empty & \\
\hline
\end{tabular}


Table 7. Changes in place specification

\begin{tabular}{|l|l|l|}
\hline Place & \multicolumn{1}{|c|}{ Colour } & \multicolumn{1}{c|}{ Meaning } \\
\hline P1 & $1^{\prime}(\mathrm{ddc}, \mathrm{cx}, \mathrm{cy}, \mathrm{cz}, \mathrm{lx}, \mathrm{ly}, \mathrm{lz}, \mathrm{cr}, \mathrm{tp}, \mathrm{nc})$ & Boxes \\
\hline P & $1^{\prime}(\mathrm{tp})$ & Type box \\
\hline CO & $1^{\prime}(\mathrm{idc}, \mathrm{cx}, \mathrm{cy}, \mathrm{cz}, \mathrm{lx}, \mathrm{ly}, \mathrm{l}, \mathrm{l}, \mathrm{cr})$ & Placed Boxes \\
\hline
\end{tabular}


Table 8. Test data for case III

\begin{tabular}{|c|c|c|c|c|}
\hline & $\begin{array}{l}\text { No. of } \\
\text { boxes }\end{array}$ & $\begin{array}{l}\text { Boxes' } \\
\text { types }\end{array}$ & $\begin{array}{l}\text { No. of } \\
\text { boxes per } \\
\text { type }\end{array}$ & $\begin{array}{l}\text { Dimensions } \\
(\mathrm{x}, \mathrm{y}, \mathrm{z})\end{array}$ \\
\hline \multirow{3}{*}{ Test 9} & \multirow{3}{*}{8} & \multirow{3}{*}{3} & 2 & $60,40,10$ \\
\hline & & & 2 & $40,35,10$ \\
\hline & & & 4 & $30,20,10$ \\
\hline \multirow{3}{*}{ Test 10} & \multirow{3}{*}{9} & \multirow{3}{*}{3} & 2 & $30,40,10$ \\
\hline & & & 5 & $40,15,10$ \\
\hline & & & 2 & $30,60,10$ \\
\hline \multirow{4}{*}{ Test 11} & \multirow{4}{*}{15} & \multirow{4}{*}{4} & 4 & $10,25,10$ \\
\hline & & & 4 & $20,40,10$ \\
\hline & & & 3 & $20,15,10$ \\
\hline & & & 4 & $40,30,10$ \\
\hline \multirow{5}{*}{ Test 12} & \multirow{5}{*}{16} & \multirow{5}{*}{5} & 6 & $10,35,10$ \\
\hline & & & 2 & $30,15,10$ \\
\hline & & & 2 & $40,40,10$ \\
\hline & & & 1 & $20,20,10$ \\
\hline & & & 5 & $20,30,10$ \\
\hline
\end{tabular}


Table 9. Feasible solutions for case III

\begin{tabular}{|c|c|c|}
\hline \multicolumn{3}{|c|}{ Test 9} \\
\hline Place & Colour & $\begin{array}{l}\text { Graphical } \\
\text { representation }\end{array}$ \\
\hline P1 & $\begin{array}{l}1^{\top}(1,40,0,0,60,40,10,0)++ \\
1^{\prime}(1,40,40,0,60,40,10,0)++ \\
1^{`}(2,0,0,0,40,35,10,0)++ \\
1^{\prime}(2,0,35,0,40,35,10,0)++ \\
1^{\prime}(3,0,70,0,20,30,10,1)++ \\
1^{`}(3,20,70,0,20,30,10,1)++ \\
1^{\prime}(3,40,80,0,30,20,10,0)++ \\
1^{\prime}(3,70,80,0,30,20,10,0)\end{array}$ & \\
\hline $\mathrm{P} 2$ & empty & \\
\hline P3 & empty & \\
\hline P4 & empty & \\
\hline \multicolumn{3}{|c|}{ Test 10} \\
\hline 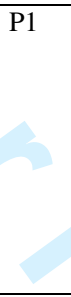 & $\begin{array}{l}1^{\top}(2,40,0,0,40,15,10,1)++ \\
1^{`}(2,55,0,0,40,15,10,1)++ \\
1^{\prime}(1,0,0,0,30,40,10,1)++ \\
1^{`}(1,0,30,0,30,40,10,1)++ \\
1^{\prime}(2,70,0,0,40,15,10,1)++ \\
1^{\prime}(2,0,60,0,40,15,10,1)++ \\
1^{\prime}(2,15,60,0,40,15,10,1)++ \\
1^{\prime}(3,40,40,0,30,60,10,1)+ \\
1^{\prime}(2,40,70,0,30,60,10,1) \\
\end{array}$ & \\
\hline P2 & $\begin{array}{l}1^{\prime}(85,0,15,40)+ \\
1^{\prime}(30,60,10,40)\end{array}$ & \\
\hline $\mathrm{P} 3$ & empty & \\
\hline $\mathrm{P} 4$ & empty & \\
\hline \multicolumn{3}{|c|}{ Test 11} \\
\hline P1 & 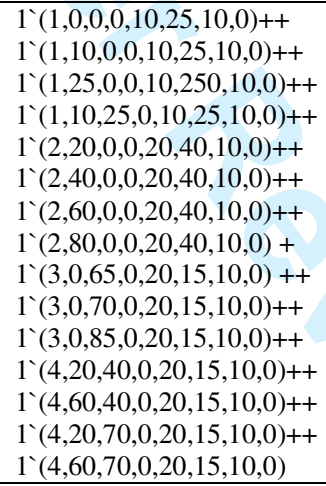 & \\
\hline $\mathrm{P} 2$ & $1^{\prime}(0,95,5,20)$ & \\
\hline P3 & empty & \\
\hline $\mathrm{P} 4$ & $1 `(0,0,100,0,0)$ & \\
\hline \multicolumn{3}{|c|}{ Test 12} \\
\hline P1 & 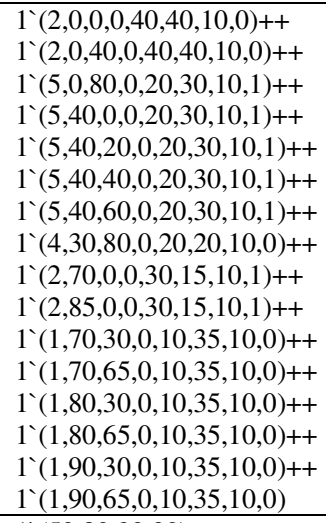 & \\
\hline $\mathrm{P} 2$ & $1^{`}(50,80,20,20)$ & \\
\hline $\mathrm{P} 3$ & empty & \\
\hline P4 & $1^{`}(0,0,400,0,0)$ & \\
\hline
\end{tabular}


Table 10. Changes in place specification

\begin{tabular}{|l|l|l|}
\hline Place & \multicolumn{1}{|c|}{ Colour } & \multicolumn{1}{c|}{ Meaning } \\
\hline P & $1^{\prime}($ scx1,scy1,slx1,sly1) & Free surface of new row \\
\hline CO & $1^{\prime}(\mathrm{idc}, \mathrm{cx}, \mathrm{cy}, \mathrm{cz}, \mathrm{lx}, \mathrm{ly}, \mathrm{lz}, \mathrm{cr})$ & Placed Boxes \\
\hline
\end{tabular}


Table 11. Test data for case IV

\begin{tabular}{|c|c|c|c|c|}
\hline & $\begin{array}{l}\text { No. of } \\
\text { boxes }\end{array}$ & $\begin{array}{l}\text { Boxes' } \\
\text { types }\end{array}$ & No. of boxes per type & $\begin{array}{l}\text { Dimensions } \\
(\mathrm{x}, \mathrm{y}, \mathrm{z})\end{array}$ \\
\hline \multirow{3}{*}{ Test 13} & \multirow{3}{*}{8} & \multirow{3}{*}{3} & 3 & $50,30,10$ \\
\hline & & & 2 & $20,40,10$ \\
\hline & & & 3 & $30,30,10$ \\
\hline \multirow{3}{*}{ Test 14} & \multirow{3}{*}{11} & \multirow{3}{*}{3} & 5 & $40,20,10$ \\
\hline & & & 3 & $40,30,10$ \\
\hline & & & 3 & $20,30,10$ \\
\hline \multirow{3}{*}{ Test 15} & \multirow{3}{*}{13} & \multirow{3}{*}{3} & 3 & $30,30,10$ \\
\hline & & & 8 & $10,30,10$ \\
\hline & & & 2 & $40,30,10$ \\
\hline \multirow{3}{*}{ Test 16} & \multirow{3}{*}{16} & \multirow{3}{*}{3} & 5 & $30,20,10$ \\
\hline & & & 5 & $70,10,10$ \\
\hline & & & 6 & $20,20,10$ \\
\hline
\end{tabular}


Table 12. Feasible solutions for case IV

\begin{tabular}{|c|c|c|}
\hline \multicolumn{3}{|c|}{ Test 13} \\
\hline Place & Colour & $\begin{array}{l}\text { Graphical } \\
\text { representation }\end{array}$ \\
\hline P1 & $\begin{array}{l}1^{\top}(1,20,0,0,50,30,10,0)++ \\
1^{\prime}(1,20,30,0,50,30,10,0)++ \\
1^{\prime}(1,20,60,0,50,30,10,0)++ \\
1^{\prime}(1,0,0,0,20,40,10,0)++ \\
1^{\prime}(1,0,40,0,20,40,10,0)++ \\
1^{\prime}(1,70,0,0,30,30,10,0)++ \\
1^{\prime}(1,70,30,0,30,30,10,0)++ \\
1^{\prime}(1,70,60,0,30,30,10,0)\end{array}$ & \\
\hline $\mathrm{P} 2$ & $\begin{array}{l}1^{`}(0,90,50,10)+1^{`}(50,80,20 \\
20)++1^{`}(70,90,30,10)\end{array}$ & \\
\hline P3 & empty & \\
\hline P4 & $1^{`}(0,0,1200,0,0)$ & \\
\hline \multicolumn{3}{|c|}{ Test 14} \\
\hline P1 & $\begin{array}{l}1^{\prime}(1,40,0,0,40,20,10,0,2)++ \\
1^{\prime}(1,40,20,0,40,20,10,0,2)+ \\
1^{\prime}(1,40,40,0,40,20,10,0,2) \\
1^{\prime}(1,40,60,0,40,20,10,0,2)+ \\
1^{\prime}(1,40,80,0,40,20,10,0,2)+ \\
1^{\prime}(1,80,0,0,20,30,10,0,2) \\
1^{\prime}(1,80,30,0,20,30,10,0,2)+ \\
1^{\prime}(1,80,60,0,20,30,10,0,2)+ \\
1^{\prime}(1,0,0,0,40,30,10,0,2) \\
1^{\prime}(1,30,0,0,40,30,10,0,2)++ \\
1^{\prime}(1,60,0,0,40,30,10,0,2)\end{array}$ & \\
\hline $\mathrm{P} 2$ & $\begin{array}{l}\text { 1` }(40,90,20,10)++ \\
1^{`}(60,90,40,10)\end{array}$ & \\
\hline $\mathrm{P} 3$ & empty & \\
\hline P4 & $1^{`}(0,0,60,0,0)$ & \\
\hline \multicolumn{3}{|c|}{ Test 15} \\
\hline P1 & 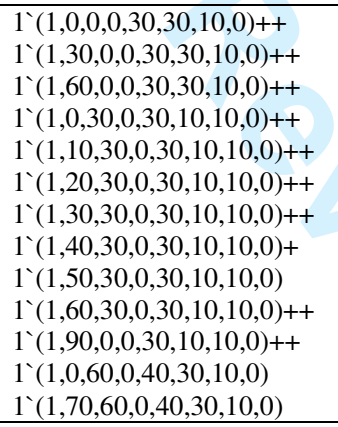 & \\
\hline $\mathrm{P} 2$ & $\begin{array}{l}1^{\prime}(30,70,30,30)++ \\
1^{\prime}(60,60,40,40)\end{array}$ & \\
\hline $\mathrm{P} 3$ & empty & \\
\hline P4 & $1^{`}(0,0,2500,0,0)$ & \\
\hline \multicolumn{3}{|c|}{ Test 16} \\
\hline P1 & 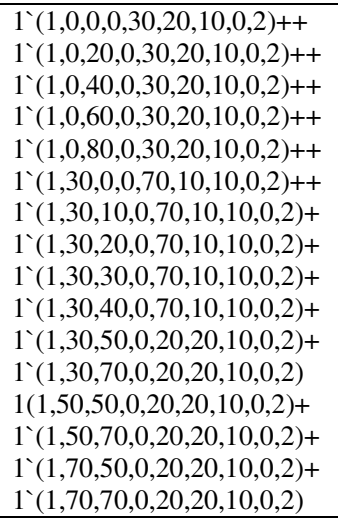 & \\
\hline $\mathrm{P} 2$ & $\begin{array}{l}1^{`}(30,90,20,10)++1^{`}(50,90, \\
20,10)++ \\
1^{`}(70,90,20,10)++1^{`}(90,50, \\
10,50)\end{array}$ & \\
\hline $\mathrm{P} 3$ & empty & \\
\hline $\mathrm{P} 4$ & $1^{\prime}(0,0,1100,0,0)$ & \\
\hline
\end{tabular}


Figure 1: Box placement casuistic \& free surfaces

Figure 2: Generation of virtual boxes

Figure 3: First 2 levels of a reachability tree

Figure 4: Box placement casuistic

Figure 5: Virtual box placement casuistic

Figure 6: Examples of virtual box placement casuistic

Figure 7: T31. Fitting a box with $1 x>$ slx and ly $>$ sly

Figure 8: Fitting a box with $1 \mathrm{x}>\mathrm{slx}, \mathrm{ly}<\mathrm{sly}, \mathrm{scx}=\mathrm{cx} \& \mathrm{scy}=\mathrm{cy}$.

Figure 9: CPN for fitting a box with $1 \mathrm{x}>\mathrm{slx}, \mathrm{ly}<\mathrm{sly}$, scx $=\mathrm{cx} \& \mathrm{scy}=\mathrm{cy}$.

Figure 10: Heuristic based on typology boxes. Transition T8. 


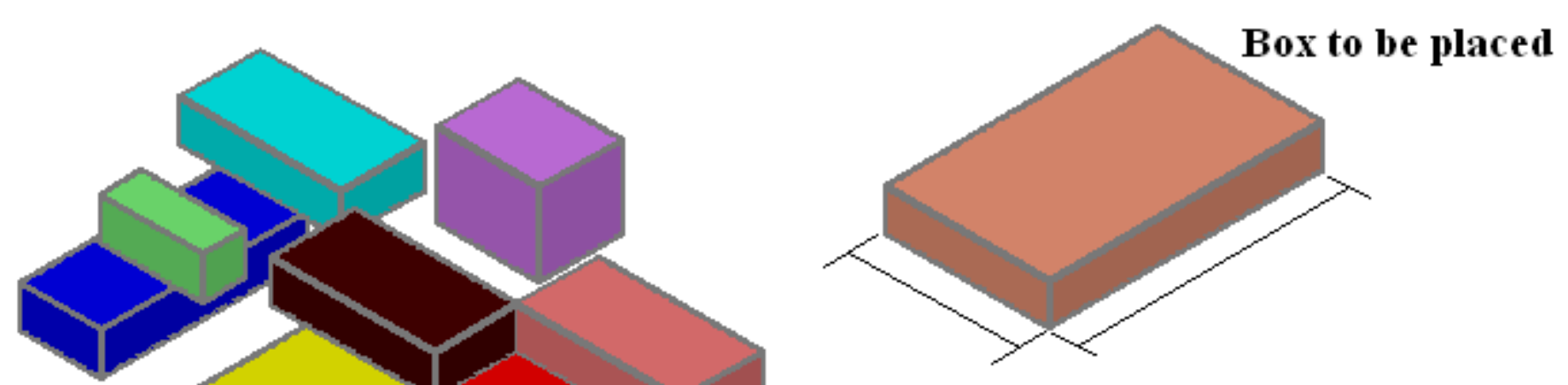

sly $_{2}<1 x \&$ ly

$\mathbf{s l x}_{2}<\mathbf{l x} \& \mathbf{l y}$

$\operatorname{slx}_{1} \& \quad$ sly $_{1}>1 x \&$ ly

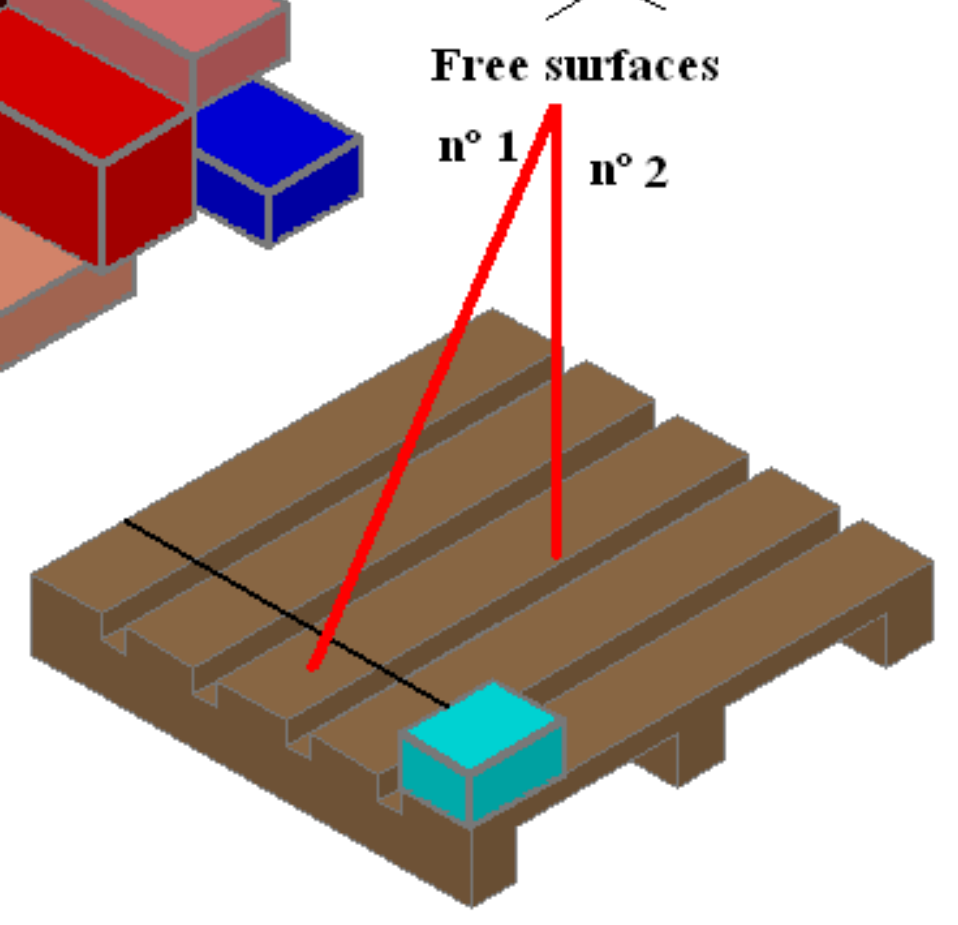

Figure 1: Box placement casuistic and free surfaces 

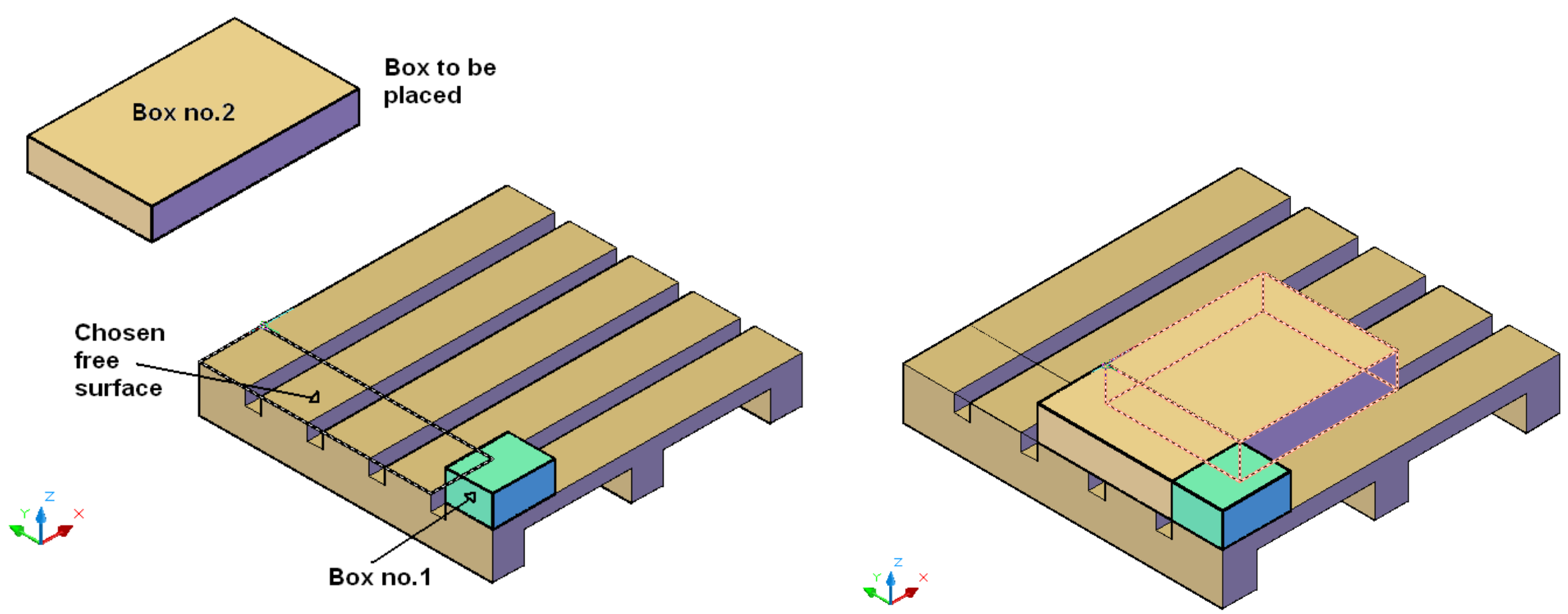

Figure 2: Generation of virtual boxes 


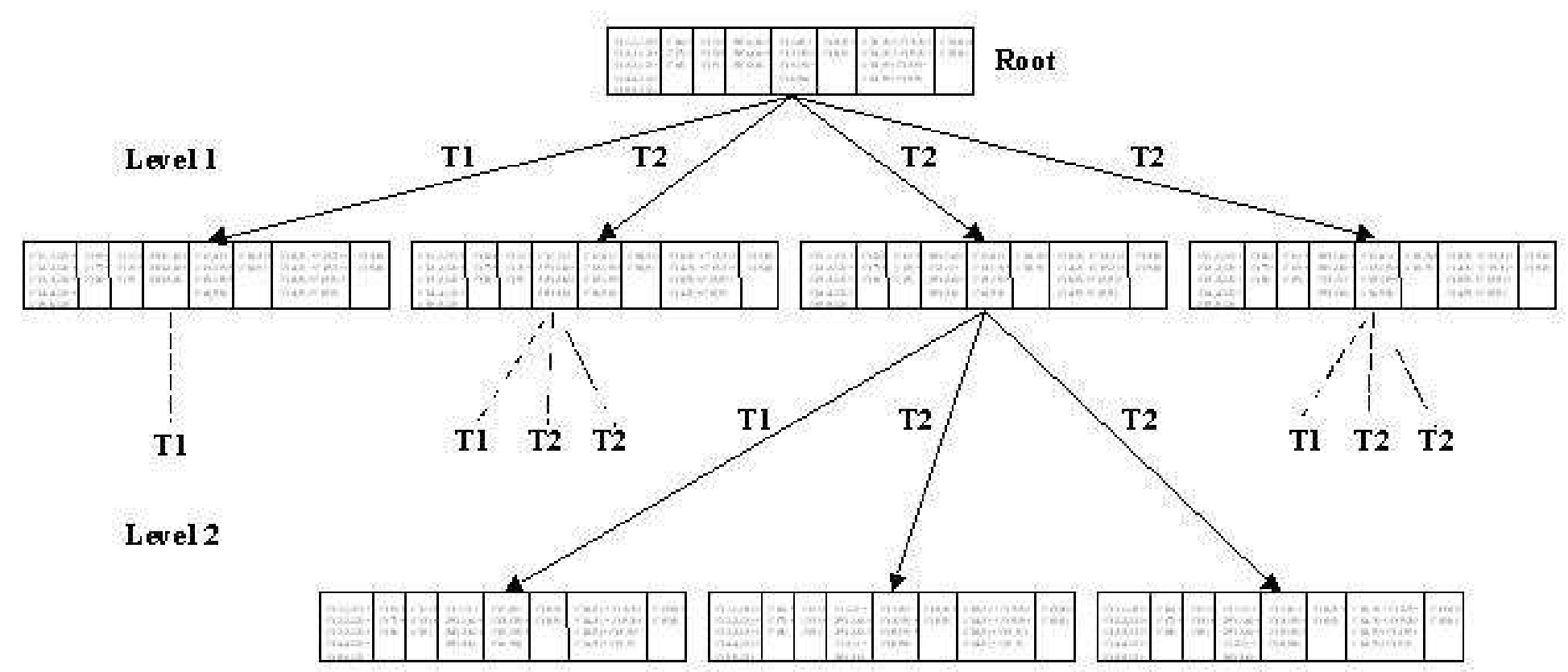

Figure 3: First 2 levels of a reachability tree 


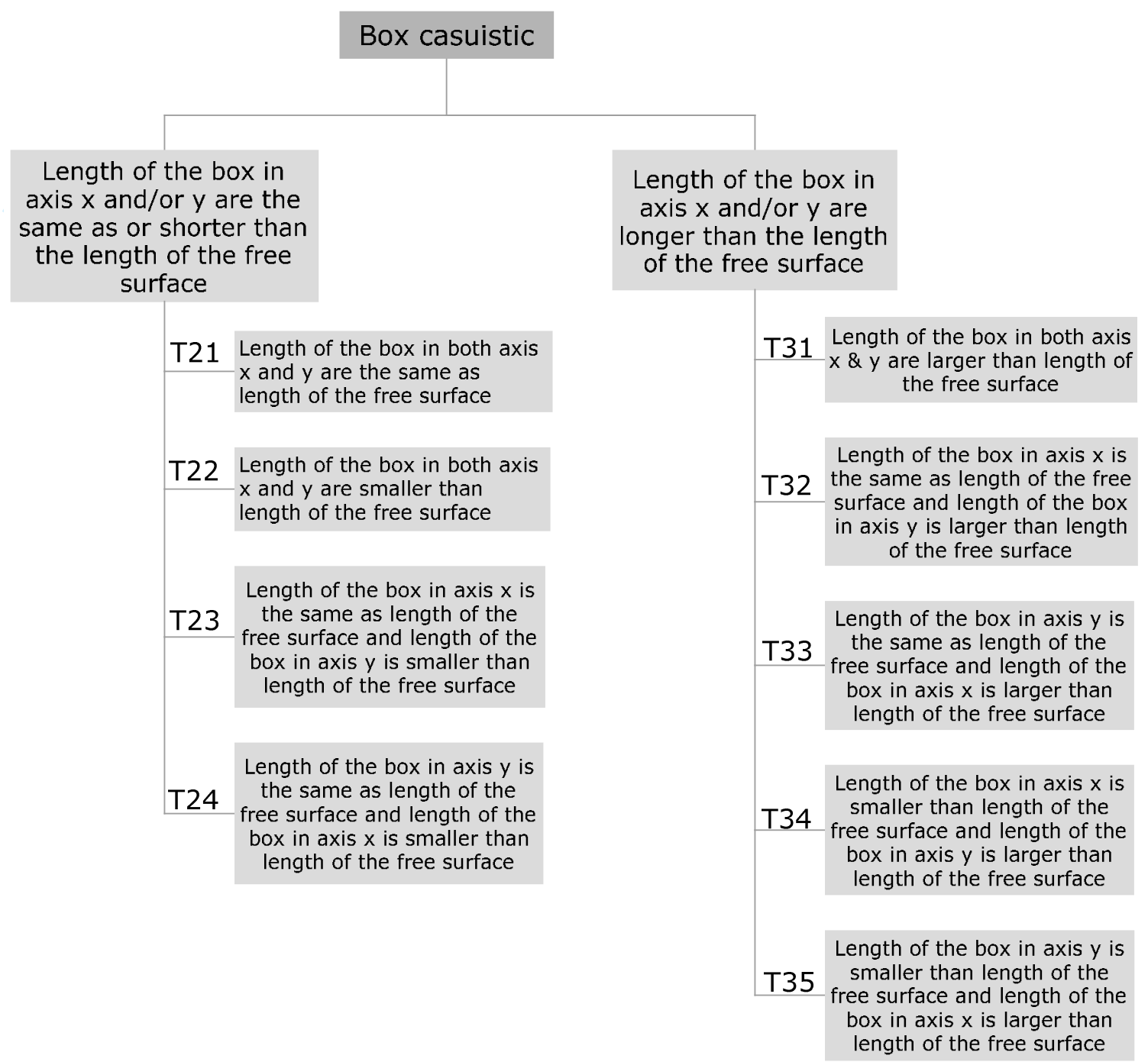

Figure 4: Box placement casuistic 


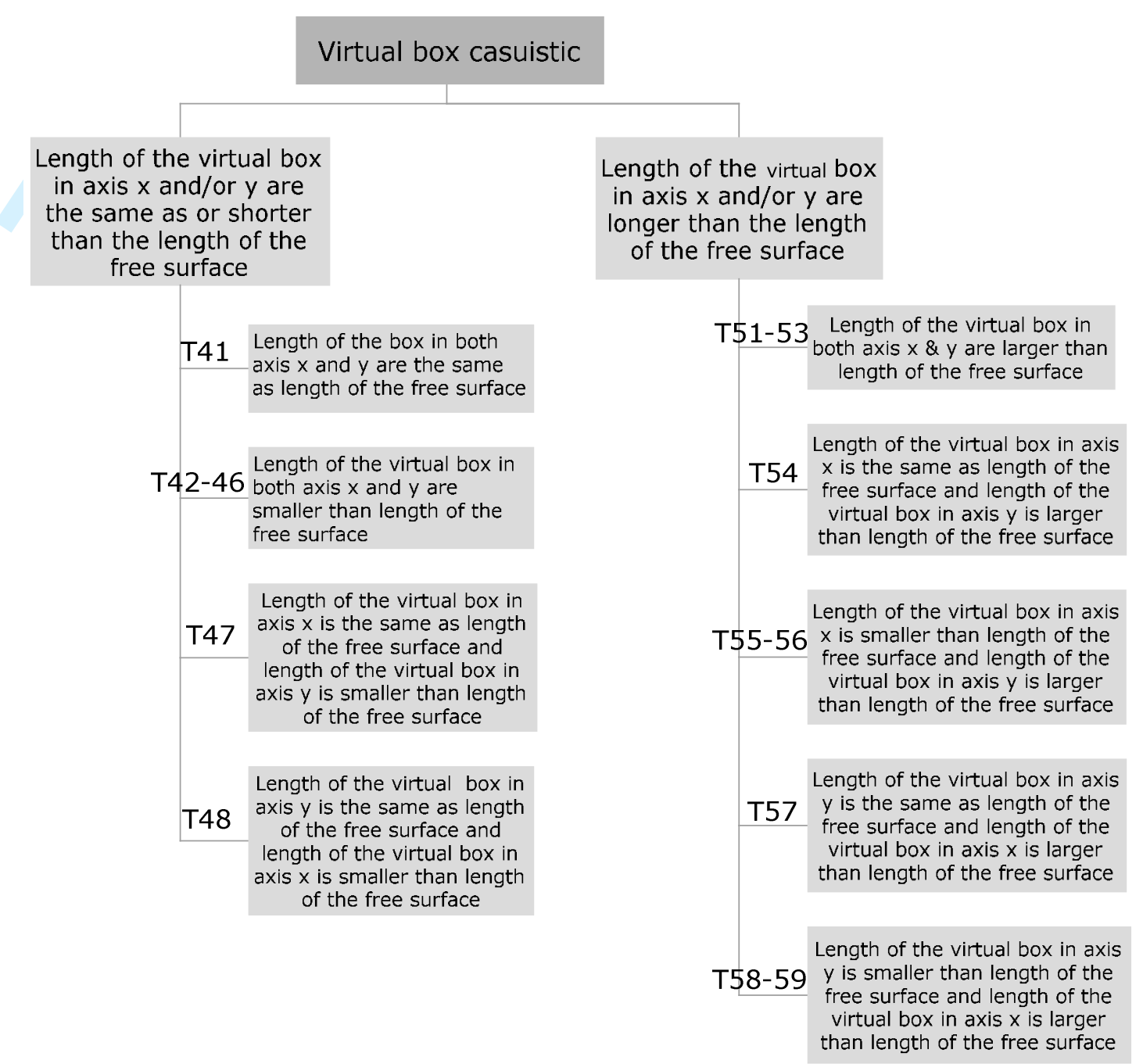

Figure 5: Virtual box placement casuistic 


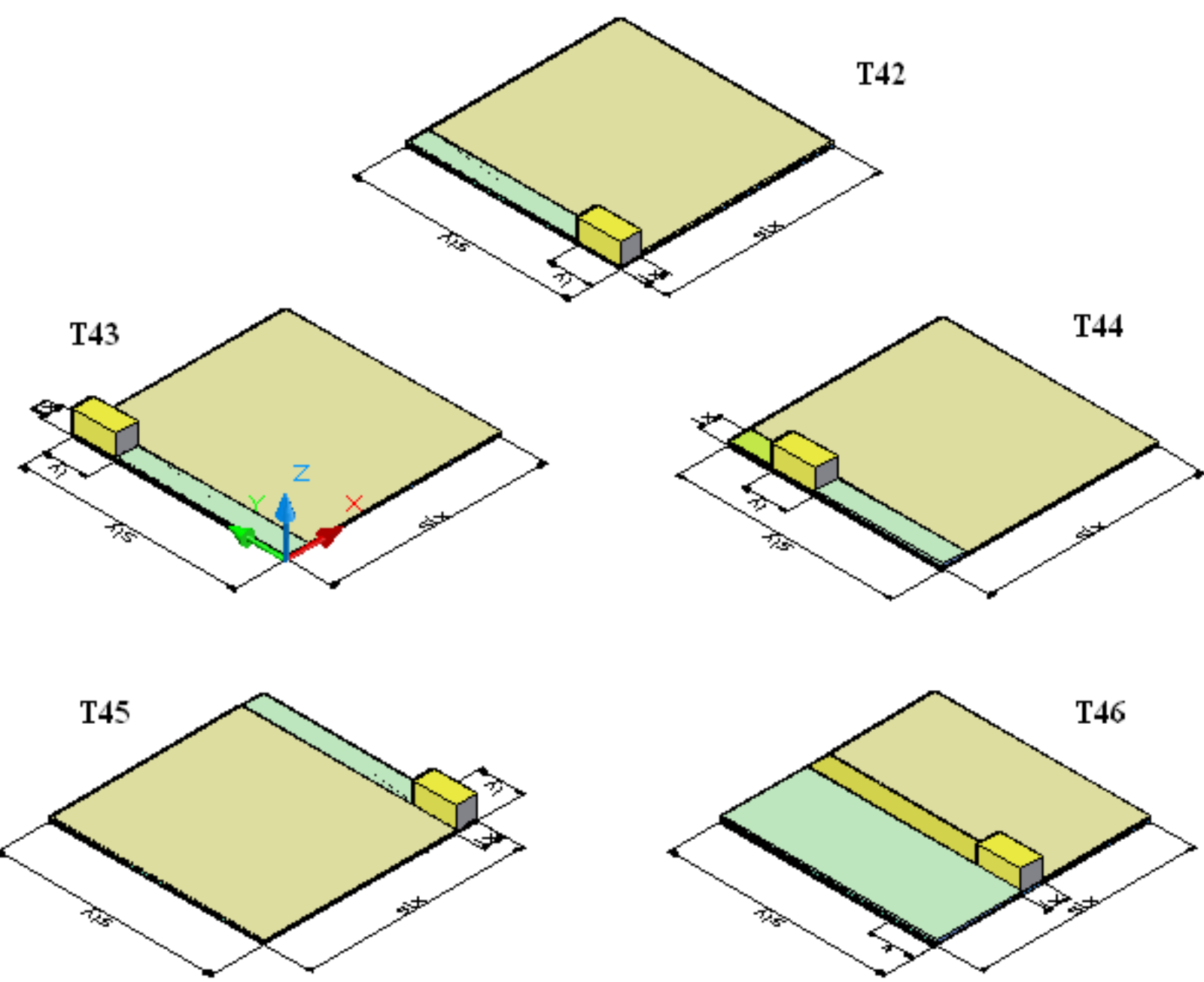

Figure 6: Examples of virtual box placement casuistic 

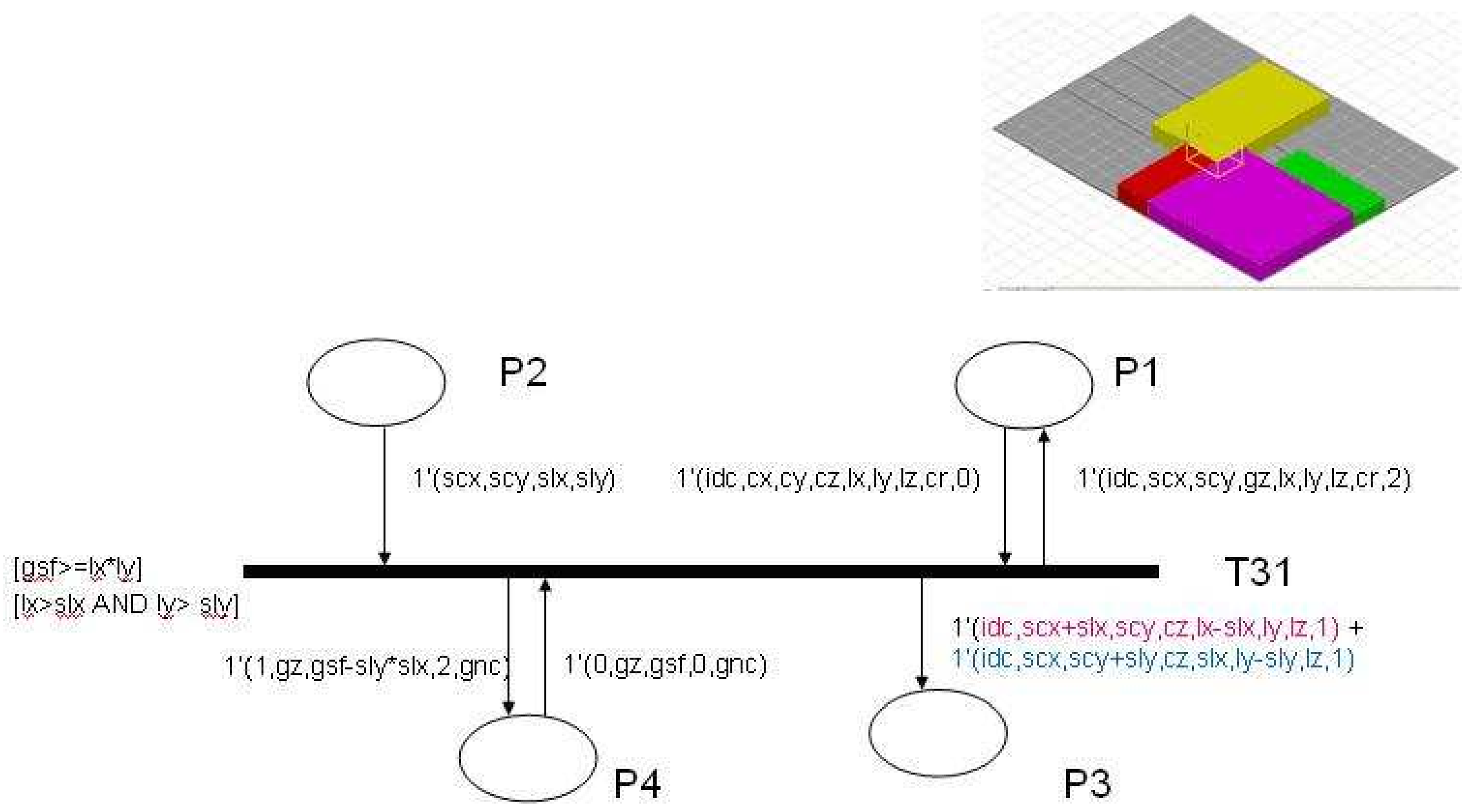

Figure7: T31. Fitting a box with $1 x>$ slx and ly $>$ sly 


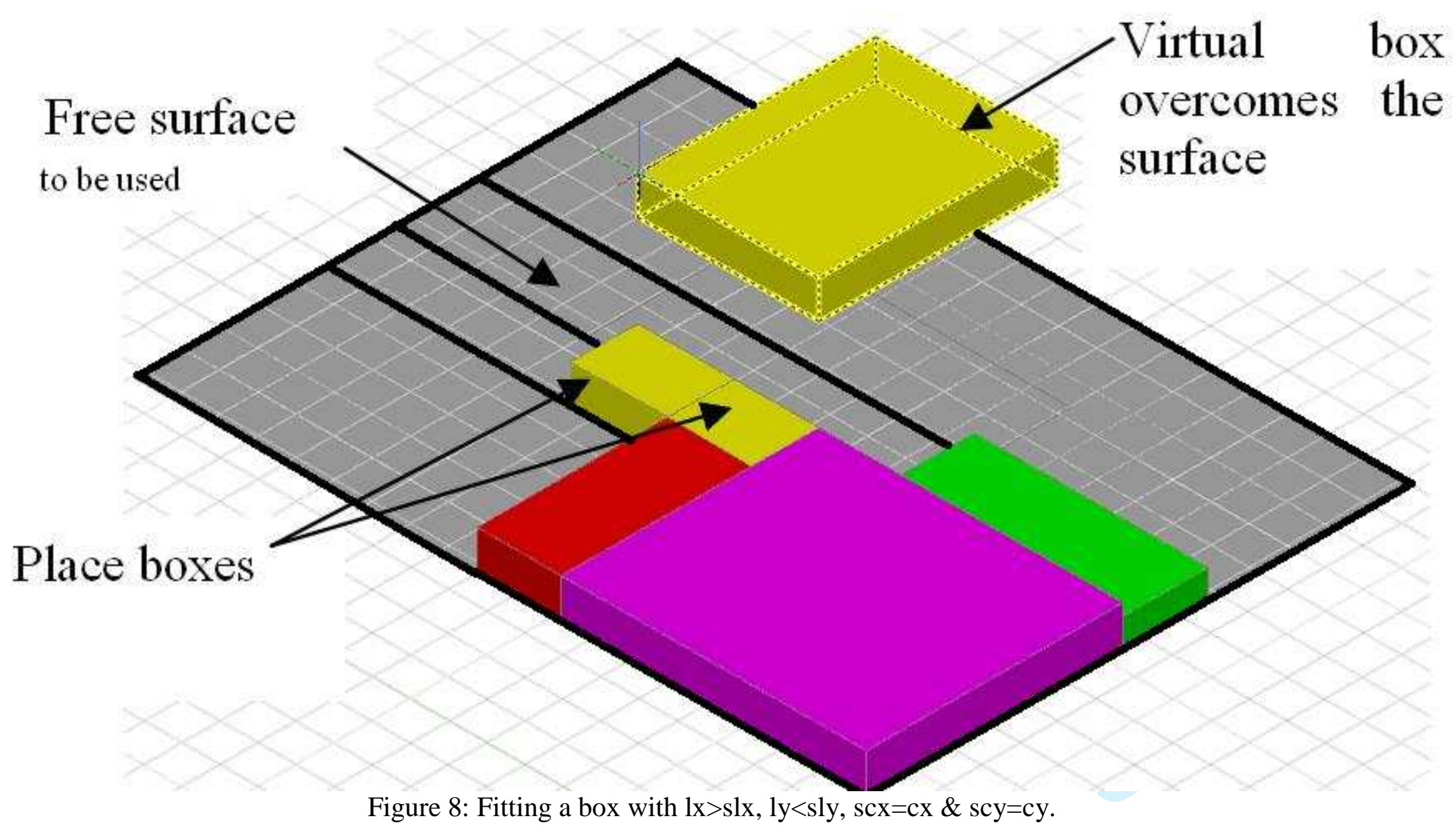

http://mc.manuscriptcentral.com/tprs Email: ijpr@lboro.ac.uk 


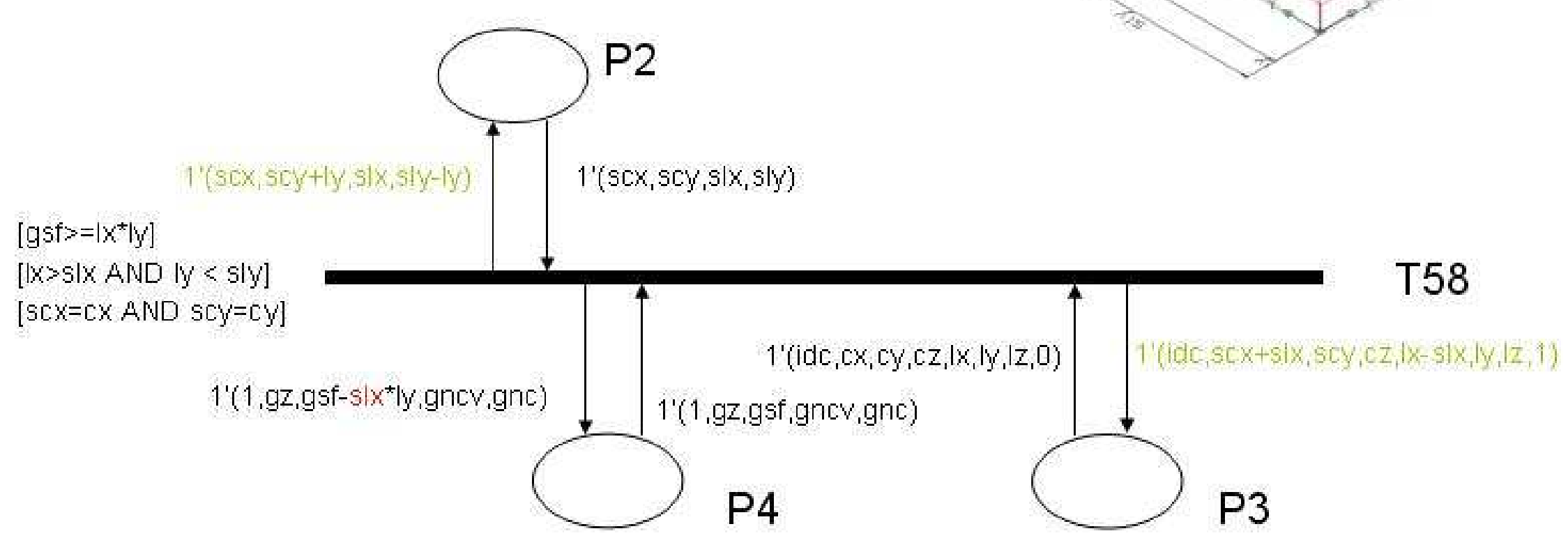

Figure 9: $\mathrm{CPN}$ for fitting a box with $1 \mathrm{x}>\mathrm{slx}, \mathrm{ly}<\mathrm{sly}, \mathrm{scx}=\mathrm{cx} \& \mathrm{scy}=\mathrm{cy}$. 


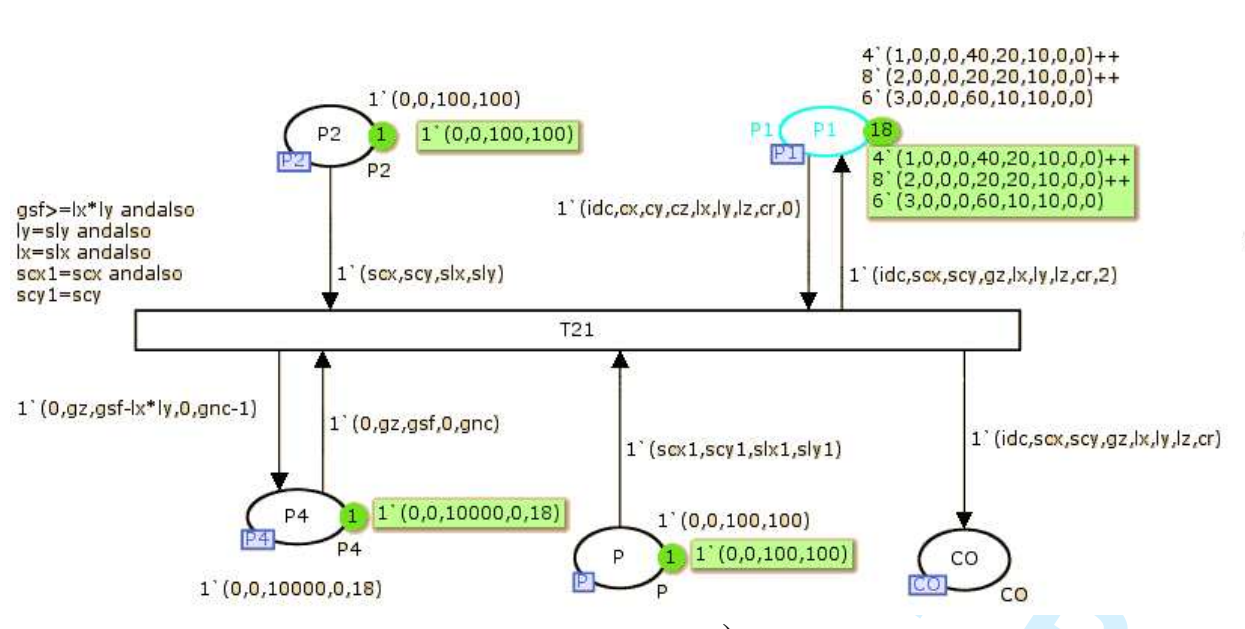

a)

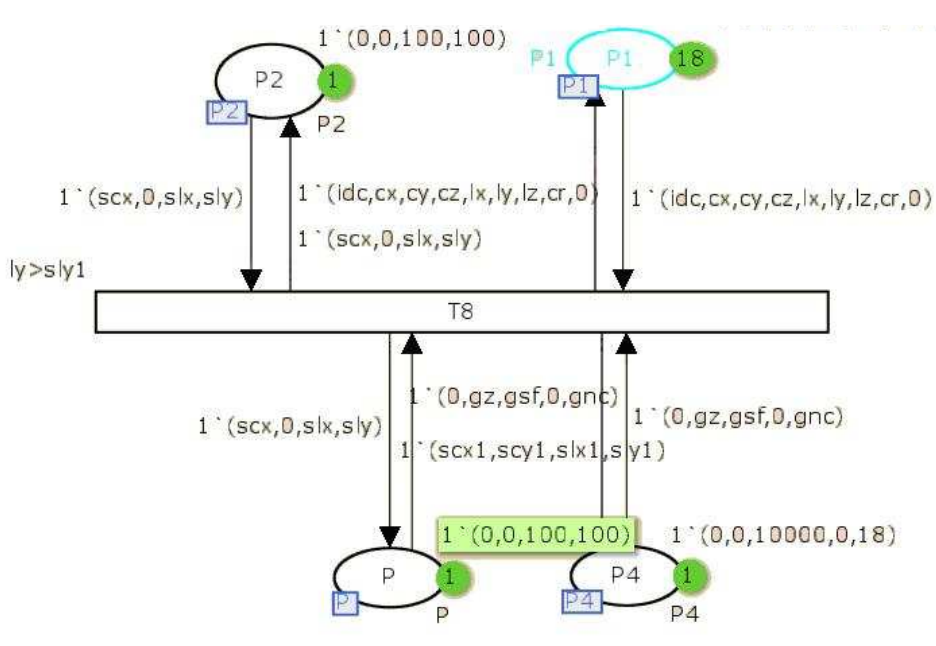

b)

Figure 10: Heuristic based on typology boxes. a)New transition. b) Modified places and colours 
Table 5:

FEASIBLE SOLUTIONS FOR CASE I

\begin{tabular}{|c|c|c|}
\hline \multicolumn{3}{|c|}{ Test 1} \\
\hline Place & Colour & Graphical representation \\
\hline P1 & $1^{\prime}(1,0,0,0,100,50,10,0,2)^{++1} 1^{`}(1,50,0,0,100,50,10,0,2)$ & \\
\hline $\mathrm{P} 2$ & empty & \\
\hline P3 & empty & \\
\hline P4 & empty & \\
\hline \multicolumn{3}{|c|}{ Test 2} \\
\hline P1 & $\begin{array}{l}l^{\prime}(1,0,0,0,20,100,10,1,2)+1^{\prime}(1,20,0,0,20,100,10,1,2)+1^{\prime}(1,40,0,0,20,100,10,1,2)+ \\
1^{\prime}(1,60,0,0,20,100,10,1,2)^{+}+1^{\prime}(1,80,0,0,20,100,10,1,2)\end{array}$ & \\
\hline P2 & empty & \\
\hline P3 & empty & \\
\hline \multirow{2}{*}{\multicolumn{3}{|c|}{ Test 3}} \\
\hline & & \\
\hline P1 & $\begin{array}{l}1^{1}(1,0,0,0,50,20,10,0,2)++1^{\prime}(1,0,20,0,50,20,10,0,2)+1^{\prime}(1,0,40,0,50,20,10,0,2)+ \\
1^{\prime}(1,0,0,0,0,50,20,10,0,2)+1^{\prime}(1,0,80,0,50,20,10,0,2)+1^{\prime}(1,50,0,0,50,20,10,0,2)+ \\
1^{\prime}(1,50,20,0,50,20,10,0,2)+11^{\prime}(1,50,40,0,50,20,10,0,2)+1^{\prime}(1,50,60,0,50,20,10,0,2)+ \\
1^{\prime}(1,50,80,0,50,20,10,0,2)\end{array}$ & \\
\hline P2 & 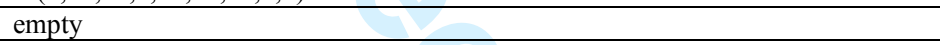 & \\
\hline $\mathrm{P} 3$ & +2 & \\
\hline $\mathrm{P} 4$ & +2 & \\
\hline \multicolumn{3}{|c|}{ Test 4} \\
\hline P1 & $\begin{array}{l}1^{1}(1,0,0,0,30,30,10,0,2)+1^{\top}(1,0,30,0,30,30,10,0,2)+1^{\top}(1,0,60,0,30,30,10,0,2)+ \\
1^{\prime}(1,30,0,0,30,30,10,0,2)+1^{\prime}(1,30,30,0,30,30,10,0,2)+1^{\prime}(1,30,60,0,30,30,10,0,2)+ \\
1^{\prime}(1,60,0,0,30,30,10,0,2)+1^{\prime}(1,60,30,0,30,30,10,0,2)+1^{\prime}(1,60,60,0,30,30,10,0,2)\end{array}$ & \\
\hline P2 & $1^{\prime}(0,90,30,10)+1^{\prime}(0,30,90,30,10)+1^{\prime}(60,90,30,10)+1^{\prime}(90,0,10,100)$ & \\
\hline P3 & empty & \\
\hline P4 & $1^{\prime}(0,0,1900,0)$ & \\
\hline \multicolumn{3}{|c|}{ Test 5} \\
\hline P1 & $\begin{array}{l}1^{\prime}(1,0,0,0,40,30,10,1,2)++1^{\prime}(1,0,30,0,30,40,10,0,2)++1^{\prime}(1,40,0,0,30,40,10,0,2)++ \\
1^{\prime}(1,40,40,0,30,40,10,0,2)+1^{\prime}(1,70,0,0,30,40,10,0,2)++1^{\prime}(1,70,40,0,30,40,10,0,2)\end{array}$ & \\
\hline $\mathrm{P} 2$ & $1^{\prime}(0,70,30,30)+1^{\prime}(30,30,10,70)+1^{\prime}(40,80,30,20)+1^{\prime}(70,80,30,20)$ & \\
\hline $\mathrm{P} 3$ & empty & \\
\hline P4 & $1^{\prime}(0,0,2800,0)$ & \\
\hline
\end{tabular}


Table 6

FEASIBLE SOLUTIONS FOR CASE II

\begin{tabular}{|c|c|c|}
\hline \multicolumn{3}{|c|}{ Test 6} \\
\hline Place & Colour & Graphical representation \\
\hline P1 & $\bar{l}^{\prime}(1,0,0,0,100,80,10,0,2)++1^{`}(1,0,80,0,100,20,10,0,2)$ & \\
\hline P2 & empty & \\
\hline P3 & empty & \\
\hline P4 & empty & \\
\hline \multicolumn{3}{|c|}{ Test 7} \\
\hline P1 & $\begin{array}{l}1^{`}(1,0,0,0,60,80,10,0,2)++1^{\prime}(1,0,80,0,60,20,10,0,2)^{+++1}(1,60,0,0,40,70,10,0,2)^{++} \\
1^{`}(1,60,70,0,40,30,10,0,2)\end{array}$ & \\
\hline P2 & empty & \\
\hline P3 & empty & \\
\hline P4 & empty & . \\
\hline \multicolumn{3}{|c|}{ Test 8} \\
\hline P1 & $\begin{array}{l}1^{\prime}(1,0,0,0,40,50,10,0,2)++1^{\prime}(1,0,50,0,40,50,10,0,2)++1^{\prime}(1,40,0,0,20,50,10,0,2)++ \\
1^{\prime}(1,40,50,0,20,50,10,0,2)+1^{\prime}(1,60,0,0,40,50,10,0,2)++1^{`}(1,60,50,0,20,50,10,0,2)+ \\
1^{\prime}(1,80,50,0,20,50,10,0,2)\end{array}$ & \\
\hline $\mathrm{P} 2$ & 2 & \\
\hline P3 & 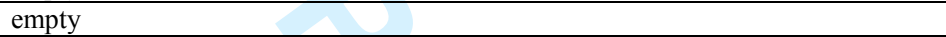 & \\
\hline P4 & empty & \\
\hline
\end{tabular}

Table 9:

FEASIBLE SOLUTIONS FOR CASE III

\begin{tabular}{|c|c|c|}
\hline \multicolumn{3}{|c|}{ Test 9} \\
\hline Place & Colour & Graphical representation \\
\hline P1 & $\begin{array}{l}1^{\prime}(1,40,0,0,60,40,10,0)++1^{`}(1,40,40,0,60,40,10,0)++1^{\prime}(2,0,0,0,40,35,10,0)++ \\
1^{\prime}(2,0,35,0,40,35,10,0)++1^{`}(3,0,70,0,20,30,10,1)^{+++1}(3,20,70,0,20,30,10,1)++ \\
1^{\prime}(3,40,80,0,30,20,10,0)++1^{`}(3,70,80,0,30,20,10,0)\end{array}$ & \\
\hline P2 & empty & \\
\hline P3 & empty & \\
\hline P4 & empty & \\
\hline \multicolumn{3}{|c|}{ Test 10} \\
\hline $\mathrm{P} 1$ & 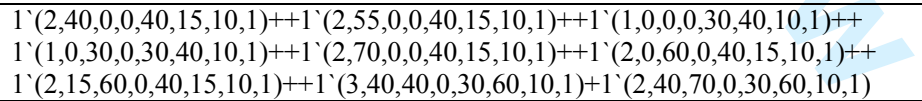 & \\
\hline $\mathrm{P} 2$ & $1^{\prime}(85,0,15,40)+1^{\prime}(30,60,10,40)$ & \\
\hline P3 & empty & \\
\hline P4 & empty & \\
\hline \multicolumn{3}{|c|}{ Test 11} \\
\hline P1 & 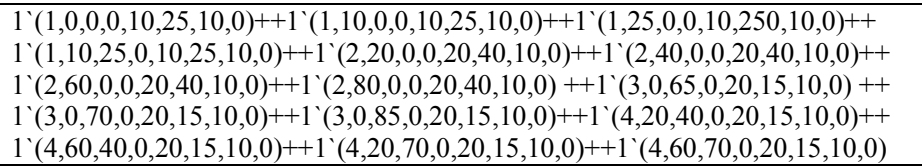 & \multirow{4}{*}{ is } \\
\hline P2 & $1^{\prime}(0,95,5,20)$ & \\
\hline P3 & empty & \\
\hline P4 & $1^{\prime}(0,0,100,0,0)$ & \\
\hline \multicolumn{3}{|c|}{ Test 12} \\
\hline P1 & 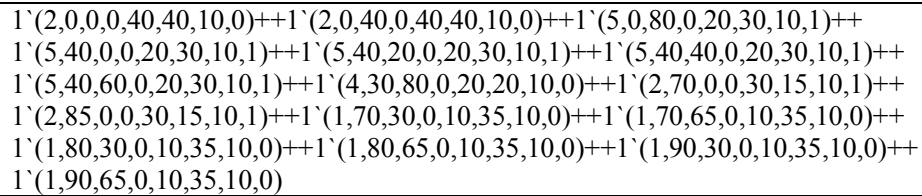 & \\
\hline $\mathrm{P} 2$ & $1^{\prime}(50,80,20,20)$ & \\
\hline $\mathrm{P} 3$ & empty & \\
\hline P4 & $1^{\prime}(0,0,400,0,0)$ & \\
\hline
\end{tabular}




\begin{tabular}{|c|c|c|}
\hline \multicolumn{3}{|c|}{ Test 13} \\
\hline Place & Colour & Graphical representation \\
\hline P1 & $\begin{array}{l}1^{\prime}(1,20,0,0,50,30,10,0)^{++1} 1^{\prime}(1,20,30,0,50,30,10,0)^{+++1}(1,20,60,0,50,30,10,0)^{++} \\
1^{\prime}(1,0,0,0,20,40,10,0)++1^{`}(1,0,40,0,20,40,10,0)^{+++1}(1,70,0,0,30,30,10,0)^{++} \\
1^{\prime}(1,70,30,0,30,30,10,0)^{++1} 1^{\prime}(1,70,60,0,30,30,10,0)\end{array}$ & \\
\hline $\mathrm{P} 2$ & $1^{\prime}(0,90,50,10)+1^{`}(50,80,20,20)++1 `(70,90,30,10)$ & \\
\hline P3 & empty & $\therefore$ \\
\hline $\mathrm{P} 4$ & $1^{\prime}(0,0,1200,0,0)$ & \\
\hline \multicolumn{3}{|c|}{ Test 14} \\
\hline P1 & $\begin{array}{l}1^{\prime}(1,40,0,0,40,20,10,0,2)++1^{\top}(1,40,20,0,40,20,10,0,2)+1^{\top}(1,40,40,0,40,20,10,0,2) \\
1(1,40,60,0,40,20,10,0,2)+1^{\prime}(1,40,80,0,40,20,10,0,2)+1^{`}(1,80,0,0,20,30,10,0,2) \\
1^{\prime}(1,80,30,0,20,30,10,0,2)+1^{`}(1,80,60,0,20,30,10,0,2)+1^{`}(1,0,0,0,40,30,10,0,2) \\
1^{\prime}(1,30,0,0,40,30,10,0,2)++1^{`}(1,60,0,0,40,30,10,0,2)\end{array}$ & \\
\hline $\mathrm{P} 2$ & $1^{\prime}(40,90,20,10)++1 `(60,90,40,10)$ & \\
\hline P3 & 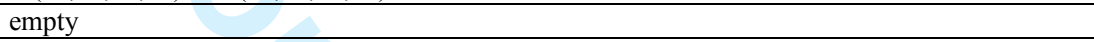 & \\
\hline P4 & $1{ }^{\prime}(0,0,60,0,0)$ & \\
\hline \multicolumn{3}{|c|}{ Test 15} \\
\hline P1 & 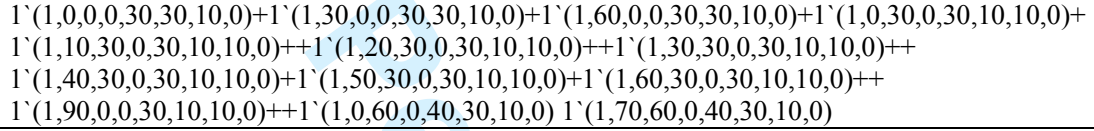 & \multirow{4}{*}{ it } \\
\hline P2 & $1^{\prime}(30,70,30,30)++1^{\prime}(60,60,40,40)$ & \\
\hline P3 & 0 & \\
\hline $\mathrm{P} 4$ & $1 `(0,0,2500,0,0)$ & \\
\hline \multicolumn{3}{|c|}{ Test 16} \\
\hline P1 & 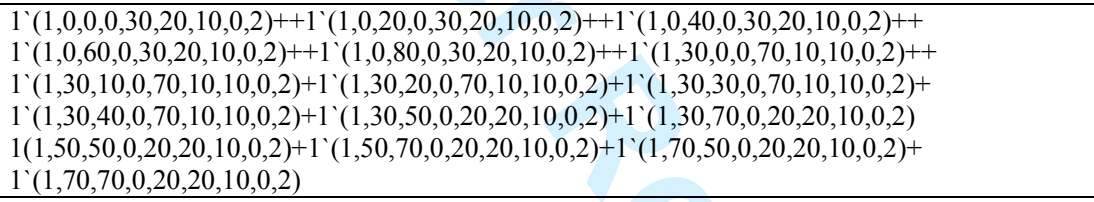 & \\
\hline $\mathrm{P} 2$ & $1^{\prime}(30,90,20,10)++1^{\prime}(50,90,20,10)++1^{`}(70,90,20,10)^{+++1} 1^{`}(90,50,10,50)$ & \\
\hline P3 & empty & \\
\hline $\mathrm{P} 4$ & $1^{`}(0,0,1100,0,0)$ & \\
\hline
\end{tabular}

